\title{
Phytoecdysteroids: A Novel, Non-Androgenic Alternative for Muscle Health and Performance
}

\author{
Kevin A Zwetsloot ${ }^{1,2}$, Andrew R Shanely ${ }^{1,2,4}$, Edward K Merritt ${ }^{1,2}$ and Jeffrey M McBride ${ }^{1,2,3 *}$ \\ ${ }^{1}$ Appalachian State University, Department of Health \& Exercise Science, Boone, NC 28607, USA \\ ${ }^{2}$ Integrated Muscle Physiology Laboratory, Boone, NC 28607, USA \\ ${ }^{3}$ Neuromuscular \& Biomechanics Laboratory, Boone, NC 28607, USA \\ ${ }^{4}$ Human Performance Laboratory, North Carolina Research Campus; Kannapolis, NC 28081, USA
}

\section{Introduction}

Skeletal muscle is the most abundant tissue in the adult human body, comprising more than $40 \%$ of total body mass in normal, healthy individuals [1], and is required for movement and locomotion. Muscle mass (volume) is an important determinant of muscle function, such that physiological cross-sectional area is correlated to peak isometric force $[2,3]$. The maintenance of skeletal muscle mass exists as a delicate balance between the rates of muscle protein synthesis and muscle protein degradation. Rates of muscle protein synthesis and degradation are finely tuned according to activity level, nutrient availability, and health status. For example, rates of muscle protein synthesis are positively influenced by exercise and nutrition, and negatively regulated by inactivity (e.g. disuse), aging (i.e. sarcopenia), and muscle wastingrelated diseases (e.g. cancer) [4]. The PI3K/Akt signaling pathway controls both catabolic and anabolic mechanisms in skeletal muscle. Activating this pathway through exercise and nutritional interventions has a positive effect on skeletal muscle. Phytoecdysteroids (PEs) are natural steroid analogs synthesized by many plant species that possess biological, pharmacological, and medicinal properties with no known side effects in mammals [5], and are believed toelicitanabolic effects on skeletal muscle, in a non-androgenic manner,via activation of the PI3K/Akt signaling pathway.

Activated Akt has at least two anti-catabolic effects: inhibition of glycogen synthase kinase (GSK)-3 $\beta$ [6] and inhibition of the ubiquitin proteasome system [7]. Eukaryotic initiation factor-2B (eIF$2 \mathrm{~B})$, a key regulatory factor of protein translation initiation [8], is a suppressed byactivated GSK-3 $\beta$ [9], thus inhibiting protein synthesis [10]. Further, activated Akt can suppress an aspect of skeletal muscle atrophy regulated by the ubiquitin proteosomesystem [7]. Proteosomal degradation requires ligation of ubiquitin to proteins by E3 ubiquitin ligases. Polyubiquitinated proteins are then marked for degradation by the proteosome. Forkhead box O1/O3 (FOXO1/3) regulates the transcription of the E3 ligases muscle ring finger 1 (MuRF-1) and muscle atrophy F box (MAFbx, aka Atogin-1) [11]. Activated Aktphosphorylates FOXO proteins, resulting in their export from the nucleus; thus suppressing transcription of the E3 ligases and muscle protein degradation [7].

During skeletal muscle hypertrophy, activated Aktstimulates mammalian target of rapamycin (mTOR) [12]. The mammalian target of rapamycin complex (mTORC1) functions as an intracellular signaling hub that stimulates muscle protein synthesis and other essential cellular processes [13]. Resistance exercise training, growth factors (insulin and insulin-like growth factor), and nutritional interventions, such as supplementation of essential amino acids, are all well-known anabolic stimuli whose signaling mechanisms converge upon mTORC1 to stimulate muscle protein synthesis [13]. In contrast, the highly anabolic nature of testosterone is independent of mTORC1 in stimulating hypertrophy and protein synthesis in skeletal muscle [14]. This review will focus on the potential of PEs to modulate these pathways and the implications of PEs for skeletal muscle health.

\section{Anabolic Effects of Phytoecdysteroids}

Ecdysteroids are a class of steroid hormones originally discovered in insectsthat control molting and other metamorphotic processes, but since have beenidentified to regulate many biochemical and physiological processes in both invertebrates and vertebrates [15]. Analogs of ecdysteroids, called phytoecdysteroids, are found in high abundance in a variety of plant species, such as Ajuga, Serratula, Silene, and Leuzea [5] and the commonly consumed spinach (Spinaciaoleracea) [16]. While their function in plants is still conjectural, it is believed that plants synthesize PEs to provide protection against plant-eating insects [17]. Avast amount of research (most of which full text versions are unavailable in English) suggests that PEs possess a broad spectrum of biological, pharmacological, and medicinal properties in mammals, with no known adverse side effects [5]. PEs elicits anabolic, hepatoprotective, immunoprotective, antioxidant, and hypoglycemic effects. Furthermore, PEs are considered adaptogenic by enhancing physical performance, promoting vitality, and enhancing resistance to stress [5]. In general, PEs are characterized as polyhydroxylated basic carbon ring structures of 27-29 carbon atoms [15]. To date, approximately 250 variants of PEs have been identified, but the most widely investigated and physiologically significant $\mathrm{PE}$ appears to be 20-hydroxyecdysone (20E).

The anabolic effects of PEs, primarily via increases in protein synthesis, have been thoroughly described in various tissues of mammals [15]; however, less is known about the anabolic effects of PEs on skeletal muscle tissue. Folklore describes Siberians consuminghardy plants (now identified as containing high levels of PEs) to enhance stamina and ward off fatigue. Early researchin this area demonstrated that a plant extract enriched in PEs increases skeletal muscle mass in young adult and growing rats [18]. More recently, 20E has been reported to increase strength in young rats and stimulate protein synthesis in muscle cells in vitro [19]. Additionally, longer treatments (five to seven days) of 20E increases muscle mass in young mice [20] and rats [21], respectively. Most intriguing is that $20 \mathrm{E}$, unlike testosterone, elicits anabolic growth effects on tissues without androgenic side effects, e.g. increased prostate or seminal vesicle mass $[22,23]$. It is believed

*Corresponding author: Jeffrey M McBride, Appalachian State University, Department of Health, Leisure \& Exercise Science, Neuromuscular \& Biomechanics Laboratory, 045 Convocation Center, Boone, NC 28607, USA, Tel: 828-262-6333. Fax: 828-262-3138; E-mail: mcbridejm@appstate.edu

Received January 29, 2014; Accepted February 20, 2014; Published February 28,2014

Citation: Zwetsloot KA, Shanely AR, Merritt EK, McBride JM (2014) Phytoecdysteroids: A Novel, Non-Androgenic Alternative for Muscle Health and Performance. J Steroids Hormon Sci S12: e001. doi:10.4172/2157-7536.S12-e001

Copyright: (c) 2014 Zwetsloot KA, et al. This is an open-access article distributed under the terms of the Creative Commons Attribution License, which permits unrestricted use, distribution, and reproduction in any medium, provided the original author and source are credited. 
that $20 \mathrm{E}$ works via a $\mathrm{G}$ protein-coupled receptor to activate the $\mathrm{PI} 3 \mathrm{~K} /$ Aktsignaling pathway, resulting in mTORC1-mediated protein synthesis [24].

\section{Implications for Use as an Anti-Sarcopenic Therapy}

The involuntary loss of skeletal muscle mass and strength that occurs as we age is termed sarcopenia. Sarcopenia is a major health burden because it is associated with functional disability, loss of independence, and premature death [25-27]. Traditional pharmacological treatments for sarcopenia, such as hormone replacement therapy, are not entirely effective or have negative side effects. With aging, the rate of skeletal muscle protein synthesis declines [28], predominately due to decreased activation of the PI3K/Akt/mTORC1 signaling pathway [29]. Furthermore, the ability of anabolic stimuli (e.g. essential amino acidsupplementation and resistance exercise training) to activate the $\mathrm{PI} 3 \mathrm{~K} / \mathrm{Akt} / \mathrm{mTORC} 1$ signaling pathway and muscle protein synthesis is blunted in aged skeletal muscle, a condition known as "anabolic resistance". Given that PEs may activate skeletal muscle protein synthesis through a non-androgenic, G protein-coupled receptor pathway, the therapeutic potential for PEs to treat anabolic resistance and to be used of as an anti-sarcopenic therapy is encouraging.

\section{Potential Aid for Post-Damage Muscle Regeneration}

Another potential therapeutic effect of PEsis their influence on systemic and cellular processes that influence muscle injury and subsequent regeneration. Evidence suggests that post-injury supplementation with PEs has a beneficial effect on skeletal muscle regeneration by increasing the size of the regenerating fibers [21]. Of course, any agent with known effects on the muscle hypertrophypromoting Akt pathway, as many PEs have, are good candidates for therapeutic treatment of muscle injury, but additional properties of phytoecdysteroids, such as their proposed anti-inflammatory and anti-fibrotic properties, might also have beneficial effects on muscle regeneration.

The negative effects of heightened inflammation on skeletal muscle are well documented [30], and it has been noted that attenuating excessive inflammation, especially through the use of natural supplements, can be beneficial to muscle regeneration [31]. Several PEs have been shown to have potent anti-inflammatory properties in experiments utilizing known pro-inflammatory factors [32,33]. Skeletal muscle exhibits enhanced proteolysis in response to the proinflammatory agent 12-O-tetradecanoylphorbol-13-acetate (TPA) [34]. TPA likely upregulates the ubiquitin proteasome pathwaythrough NFkB. NFkB is a molecular regulator that has been implicated in slowing of the muscle regeneration process [35]. However, Sun and Yasukawa have proven that several PEs have inhibitory effects on TPA-induced inflammation [32]. Likewise, carrageenan is a known pro-inflammatory agent which negatively affects muscle strength [36]. Ochieng et al. have noted a powerful inhibitory effect of isolated PEs on carrageenan-induced inflammation [33], but others have suggested that some PEs do not have anti-inflammatory properties $[37,38]$. While these results are not definitive proof that PEs can modulate skeletal muscle damage due to inflammation, further research is certainly warranted to explore the potential therapeutic potential of PEs to modulate skeletal muscle inflammation and enhance regeneration.

Skeletal muscle fibrosis is often a negative consequence of the regeneration response following injury [39]. Dysregulation of TGF- $\beta 1$ and SMAD signaling [40], as well as aberrant matrix metalloproteinase activity [41], contribute to fibrosis and prevent optimal functional regeneration of skeletal muscle. Preventing the formation of this excessive connective tissue helps to better restore function to the injured muscles[42]. Unfortunately, these effects have yet to be studied in a model of skeletal muscle damage utilizing PEs as a potential treatment. Evidencefrom other tissues,such as skin [43] and kidney [44], implicates PEs as potential regulators of fibrosis through their actions on matrix metalloproteinases and TGF- $\beta 1$. The logical next step in understanding the effects of PEs on muscle damage is to explore their role in aiding regeneration through these same mechanisms by which they benefit other tissues.

\section{Implications for Athletic Performance Enhancement}

Synthetic forms of anabolic-androgenic steroids have been extensively studied for possible enhancement of athletic performance [45]. However, several adverse side effects have been documentedwith their usage [46]. As an alternative, anecdotal evidence indicates that various sport coaches may have experimented with deriving these effects from PEs. While there are several structural similarities between PEs and mammalian steroid hormones, they differ in the mechanism by which they induce anabolic signalingtransduction [5]. As previously mentioned, in humans PEs possess anabolic, hepatoprotective, immunoprotective, and hypoglycemic effects. Limited data in humans is available as to whether the anabolic effects would be significant enough to translate into meaningful changes in actual athletic performance. Comparisons between PE and anabolic steroid effectiveness have occurred primarily in animal models. One investigation reported that both PEs and methandrostenolone stimulate biosynthesis of myofibrillar proteins to a similar extent in mice [47]. Studies in human models are limited, but Wilborn et al. [48] examined PE supplementation on changes in muscle strength, muscular endurance, anaerobic capacity, and body compositionin resistance-trained males. This study reported no significant effect of PE supplementation on any of the measured variables. There are currently manycommercially available nutritional supplements on the market that contain PEs and PEs are also present in several food sources such as spinach, quinoa, and suma root. However, the World Anti-Doping Agency currently has PEs listed on the banned substance list for their use as performance enhancement, therefore use by athletes under this governing body is not allowed. While the actual effectiveness of PEs on human athletic performance is still questionable, further research is needed to determine the performance enhancement of PEs in human models.

\section{Conclusion}

An abundance of data exists on the anabolic effects of PEs in rodent models with limited adverse side effects. The non-androgenic nature of PEs on tissues makes investigation of PEs on skeletal muscle and theirpotential use for attenuating sarcopenia, treating post-damage muscle regeneration, and enhancing athletic performance intriguing. However, data from supplementation of PEs in human models are still limited. Whilethe potential useof PEs forenhancing skeletal muscle health and performance is promising, conclusions are tentative.

\section{References}

1. Hoppeler H (1990) The different relationship of VO2max to muscle mitochondria in humans and quadrupedal animals. Respir Physiol 80: 137-145.

2. Gans C (1982) Fiber architecture and muscle function. Exerc Sport Sci Rev 10: $160-207$

3. Sacks RD, Roy RR (1982) Architecture of the hind limb muscles of cats functional significance. J Morphol 173: 185-195. 
Citation: Zwetsloot KA, Shanely AR, Merritt EK, McBride JM (2014) Phytoecdysteroids: A Novel, Non-Androgenic Alternative for Muscle Health and Performance. J Steroids Hormon Sci S12: e001. doi:10.4172/2157-7536.S12-e001

4. Phillips BE, Hill DS, Atherton PJ (2012) Regulation of muscle protein synthesis in humans. Curr Opin Clin Nutr Metab Care 15: 58-63.

5. Báthori M, Tóth N, Hunyadi A, Márki A, Zádor E (2008) Phytoecdysteroids and anabolic-androgenic steroids--structure and effects on humans. Curr Med Chem 15: 75-91.

6. Childs TE, Spangenburg EE, Vyas DR, Booth FW (2003) Temporal alterations in protein signaling cascades during recovery from muscle atrophy. Am J Physiol Cell Physiol 285: C391-398.

7. Bonaldo P, Sandri M (2013) Cellular and molecular mechanisms of muscle atrophy. Dis Model Mech 6: 25-39.

8. Mohammad-Qureshi SS, Jennings MD, Pavitt GD (2008) Clues to the mechanism of action of elF2B, the guanine-nucleotide-exchange factor for translation initiation. Biochem Soc Trans 36: 658-664.

9. Welsh GI, Stokes CM, Wang X, Sakaue H, Ogawa W, et al. (1997) Activation of translation initiation factor elF2B by insulin requires phosphatidyl inositol 3-kinase. FEBS Lett 410: 418-422.

10. Goodman CA, Mayhew DL, Hornberger TA (2011) Recent progress toward understanding the molecular mechanisms that regulate skeletal muscle mass. Cell Signal 23: 1896-1906.

11. Sandri M, Sandri C, Gilbert A, Skurk C, Calabria E, et al. (2004) Foxo transcription factors induce the atrophy-related ubiquitin ligase atrogin-1 and cause skeletal muscle atrophy. Cell 117: 399-412.

12. Bodine SC, Stitt TN, Gonzalez M, Kline WO, Stover GL, et al. (2001) Akt/mTOR pathway is a crucial regulator of skeletal muscle hypertrophy and can prevent muscle atrophy in vivo. Nat Cell Biol 3: 1014-1019.

13. Hoppeler H, Baum O, Lurman G, Mueller M (2011) Molecular mechanisms of muscle plasticity with exercise. Compr Physiol 1: 1383-1412.

14. West DW, Phillips SM (2010) Anabolic processes in human skeletal muscle: restoring the identities of growth hormone and testosterone. Phys Sportsmed 38: 97-104.

15. Dinan L (2001) Phytoecdysteroids: biological aspects. Phytochemistry 57: 325339.

16. Adler JH, Grebenok RJ (1999) Occurrence, biosynthesis, and putative role of ecdysteroids in plants. Crit Rev Biochem Mol Biol 34: 253-264.

17. BergamascoR, HornDHS (1983) Distribution and role of insect hormones in plants. Endocrinology of Insects. New York, A.R. LissInc: 627-654.

18. Syrov VN, Kurmukov AG (1976) [Anabolic activity of phytoecdysoneecdysterone isolated from Rhaponticumcarthamoides (Willd.) Iljin]. Farmakol Toksikol 39: 690-693.

19. Gorelick-Feldman J, Maclean D, llic N, Poulev A, Lila MA, et al. (2008) Phytoecdysteroids increase protein synthesis in skeletal muscle cells. J Agric Food Chem 56: 3532-3537.

20. Cheng DM, Kutzler LW, Boler DD, Drnevich J, Killefer J, et al. (2013) Continuous infusion of 20-hydroxyecdysone increased mass of triceps brachii in C57BL/6 mice. Phytother Res 27: 107-111.

21. Tóth N, Szabó A, Kacsala P, Héger J, Zádor E (2008) 20-Hydroxyecdysone increases fiber size in a muscle-specific fashion in rat. Phytomedicine 15: 691 698.

22. Syrov VN (1984) [Mechanism of the anabolic action of phytoecdisteroids in mammals]. Nauchnye Doki Vyss Shkoly Biol Nauki: 16-20.

23. SyrovVN (2000)Comparative experimental investigation of the anabolic activity of phytoecdysteroids and steranabols. Pharmaceutical Chemistry Journal 34 : 193-197.

24. Gorelick-Feldman J, Cohick W, Raskin I (2010) Ecdysteroids elicit a rapid Ca2+ flux leading to Akt activation and increased protein synthesis in skeletal muscle cells. Steroids 75: 632-637.

25. Doherty TJ (2003) Invited review: Aging and sarcopenia. J Appl Physiol (1985) 95: 1717-1727.

26. Nair KS (2005) Aging muscle. Am J Clin Nutr 81: 953-963.

27. Buford TW, Anton SD, Judge AR, Marzetti E, Wohlgemuth SE, et al. (2010) Models of accelerated sarcopenia: critical pieces for solving the puzzle of agerelated muscle atrophy. Ageing Res Rev 9: 369-383.
28. Balagopal P, Rooyackers OE, Adey DB, Ades PA, Nair KS (1997) Effects of aging on in vivo synthesis of skeletal muscle myosin heavy-chain and sarcoplasmic protein in humans. Am J Physiol 273: E790-800.

29. Fry CS, Drummond MJ, Glynn EL, Dickinson JM, Gundermann DM, et al. (2011) Aging impairs contraction-induced human skeletal muscle mTORC1 signaling and protein synthesis. Skelet Muscle 1: 11

30. Peterson JM, Guttridge DC (2008) Skeletal muscle diseases, inflammation, and NF-kappaB signaling: insights and opportunities for therapeutic intervention. Int Rev Immunol 27: 375-387.

31. Urso ML (2013) Anti-inflammatory interventions and skeletal muscle injury: benefit or detriment? J Appl Physiol (1985) 115: 920-928.

32. Sun Y, Yasukawa K (2008) New anti-inflammatory ergostane-type ecdysteroids from the sclerotium of Polyporusumbellatus. Bioorg Med Chem Lett 18: 3417 3420 .

33. Ochieng CO, Ishola IO, Opiyo SA, Manguro LA, Owuor PO, et al. (2013) Phytoecdysteroids from the stem bark of Vitexdoniana and their antiinflammatory effects. Planta Med 79: 52-59.

34. Wyke SM, Tisdale MJ (2006) Induction of protein degradation in skeletal muscle by a phorbol ester involves upregulation of the ubiquitin-proteasome proteolytic pathway. Life Sci 78: 2898-2910.

35. Cai D, Frantz JD, Tawa NE Jr, Melendez PA, Oh BC, et al. (2004) IKKbeta/NFkappaB activation causes severe muscle wasting in mice. Cell 119: 285-298.

36. Pinniger GJ, Lavin T, Bakker AJ (2012) Skeletal muscle weakness caused by carrageenan-induced inflammation. Muscle Nerve 46: 413-420.

37. TaniguchiSF, Bersani-Amado CA, Sudo LS, AssefSMC, OgaS (1997) Effect of Pfaffiairesinoides on the experimental inflammatory process in rats. Phytother Res 11: 568-571.

38. Harmatha J, Vokác K, Kmonícková E, Zídek Z (2008) Lack of interference of common phytoecdysteroids with production of nitric oxide by immune-activated mammalian macrophages. Steroids 73: 466-471.

39. Lieber RL, Ward SR (2013) Cellular mechanisms of tissue fibrosis. 4. Structural and functional consequences of skeletal muscle fibrosis. Am J Physiol Cell Physiol 305: C241-252.

40. MacDonald EM, Cohn RD (2012) TGFî ${ }^{2}$ signaling: its role in fibrosis formation and myopathies. Curr Opin Rheumatol 24: 628-634.

41. Li H, Mittal A, Makonchuk DY, Bhatnagar S, Kumar A (2009) Matrix metalloproteinase-9 inhibition ameliorates pathogenesis and improves skeletal muscle regeneration in muscular dystrophy. Hum Mol Genet 18: 2584-2598.

42. Mourkioti $F$, Kratsios $P$, Luedde $T$, Song $Y H$, Delafontaine $P$, et al. (2006) Targeted ablation of IKK2 improves skeletal muscle strength, maintains mass, and promotes regeneration. J Clin Invest 116: 2945-2954.

43. Nsimba RY, Kikuzaki H, Konishi Y (2008) Ecdysteroids act as inhibitors of calf skin collagenase and oxidative stress. J Biochem Mol Toxicol 22: 240-250.

44. Hung TJ, Chen WM, Liu SF, Liao TN, Lee TC, et al. (2012) 20-Hydroxyecdysone attenuates TGF-î21-induced renal cellular fibrosis in proximal tubule cells. $J$ Diabetes Complications 26: 463-469.

45. Hartgens F, Kuipers H (2004) Effects of androgenic-anabolic steroids in athletes. Sports Med 34: 513-554.

46. Maravelias C, Dona A, Stefanidou M, Spiliopoulou C (2005) Adverse effects of anabolic steroids in athletes. A constant threat. ToxicolLett 158: 167-175.

47. SemeÄ kin AV, StanevskaiaTlu, Chermnykh NS, Sergeev PV (1991) [The mechanism of the thymolytic action of anabolic steroids]. Farmakol Toksikol $54: 37-38$

48. Wilborn CD, Taylor LW, Campbell BI, Kerksick C, Rasmussen CJ, et al. (2006) Effects of methoxyisoflavone, ecdysterone, and sulfo-polysaccharide supplementation on training adaptations in resistance-trained males. J IntSoc Sports Nutr 3: 19-27. 